\title{
Tumor size is an independent risk predictor for metachronous colorectal cancer
}

\author{
Takaharu Kato ${ }^{1,2}$, Sergio Alonso², Yuta Muto ${ }^{1}$, Manuel Perucho ${ }^{2,3,4}$ and Toshiki \\ Rikiyama $^{1}$ \\ ${ }^{1}$ Department of Surgery, Saitama Medical Center, Jichi Medical University, Omiya-ku, Saitama, Japan \\ ${ }^{2}$ Institute of Predictive and Personalized Medicine of Cancer (IMPPC), Institut d'investigació en ciéncies de la salut Germans \\ Trias I Pujol, (IGTP), Badalona, Barcelona, Spain \\ 3 Sanford Burnham Prebys Medical Discovery Institute, La Jolla, CA, USA \\ ${ }^{4}$ Institució Catalana de Recerca i Estudis Avançats (ICREA), Barcelona, Spain \\ Correspondence to: Takaharu Kato, email: tkato@jichi.ac.jp
}

Keywords: colorectal cancer, metachronous colorectal cancer, synchronous colorectal cancer, multiple colorectal cancers, tumor size

Received: February 05, $2016 \quad$ Accepted: February 11, 2016 Published: February 21, 2016

\section{ABSTRACT}

Non-hereditary colorectal cancer (CRC) patients are at higher risk of developing independent metachronous CRC than cancer-naïve individuals, but the reason is unknown. We studied metachronous CRC risk factors among one thousand five Japanese CRC patients who underwent surgery for CRC.

Relative hazard risk of clinical and pathological features was assessed by univariate and multivariate Cox's proportional hazard regression analysis. Observed metachronous CRC incidence was also compared with the expected cancer incidence of the general population in Japan.

Twenty-seven metachronous CRCs developed in 24 patients $(2.4 \%)$ during a follow-up period of 3,676 person-years. Multivariate analysis revealed two factors associated with a high metachronous CRC risk: synchronous CRC $(H R=6.13 ; p=$ $\left.1.3 \times 10^{-4}\right)$ and tumor size $\geq 6.5 \mathrm{~cm}\left(H R=4.34 ; p=1 \times 10^{-3}\right)$. Patients with either synchronous or large solitary tumors exhibited a higher risk for metachronous CRC than patients with solitary small tumors $\left(H R=7.3 ; p=4.3 \times 10^{-6}\right)$ and that the general Japanese population (SIR $\left.=7.01 ; p=3.5 \times 10^{-9}\right)$, while patients with solitary small tumors did not $(S I R=1.07 ; p=0.8)$. If patients younger than 60 years were excluded, the observations remained unchanged, with tumor size becoming stronger predictor $\left(H R=5.67 ; p=1.7 \times 10^{-4}\right)$ than the presence of synchronous CRC $(H R=5.34 ; p=$ $\left.9.6 \times 10^{-4}\right)$.

Our novel finding that primary tumor size is a strong independent risk factor for metachronous CRC increases the sensitivity of prediction more than twice the presence of synchronous CRC. Our data provides new insights to assess the risk for metachronous lesions that should improve the surveillance regimen for CRC.

\section{INTRODUCTION}

Colorectal cancer (CRC) is one of the most prevalent cancers in developed countries [1]. The incidence of CRC has increased lately two to four-fold in Asian countries [26]. CRC prognosis has steadily improved due to both more efficient early-stage detection and advances in treatment. However, non-hereditary CRC patients are at higher risk to develop second independent, i.e. metachronous, malignancies [7]. The reason why metachronous cancers occur at higher rates in cancer survivors than in a cancer-naïve population remains an open question [8]. Surveillance recommendations for CRC patients include a colonoscopy examination within the first year after surgery. Regrettably, adherence to this recommendation ranges from $18-61 \%$ of the patients [9], and a significant proportion of metachronous CRC lesions remain undetected until the first post-operatory surveillance 
colonoscopy, when they have already progressed to cancer. Therefore, identification of individuals at higher risk could improve patient post-operatory management by implementing a personalized, more effective surveillance plan and treatment. We investigated the clinical and pathological features of Japanese CRC patients to determine the relative contribution of the different risk factors to develop metachronous CRCs. We report here that tumor size is a novel predictor for metachronous CRC development, that together with the presence of synchronous tumors increases the precision of risk assessment.

\section{RESULTS}

We recruited 1,022 consecutive patients that underwent surgery for CRC at Saitama Medical Center. Of these, 17 individuals with hereditary syndromes, previous history of CRC, or ulcerative colitis (UC) were excluded (Figure 1). Of the remaining 1,005 patients (Table S1), 24 individuals developed metachronous CRC during followup of 3,676 person-years (Table S2). Ninety-three patients who had undergone palliative surgery (as opposed to intended curative surgery) were further excluded because

\section{Study design}

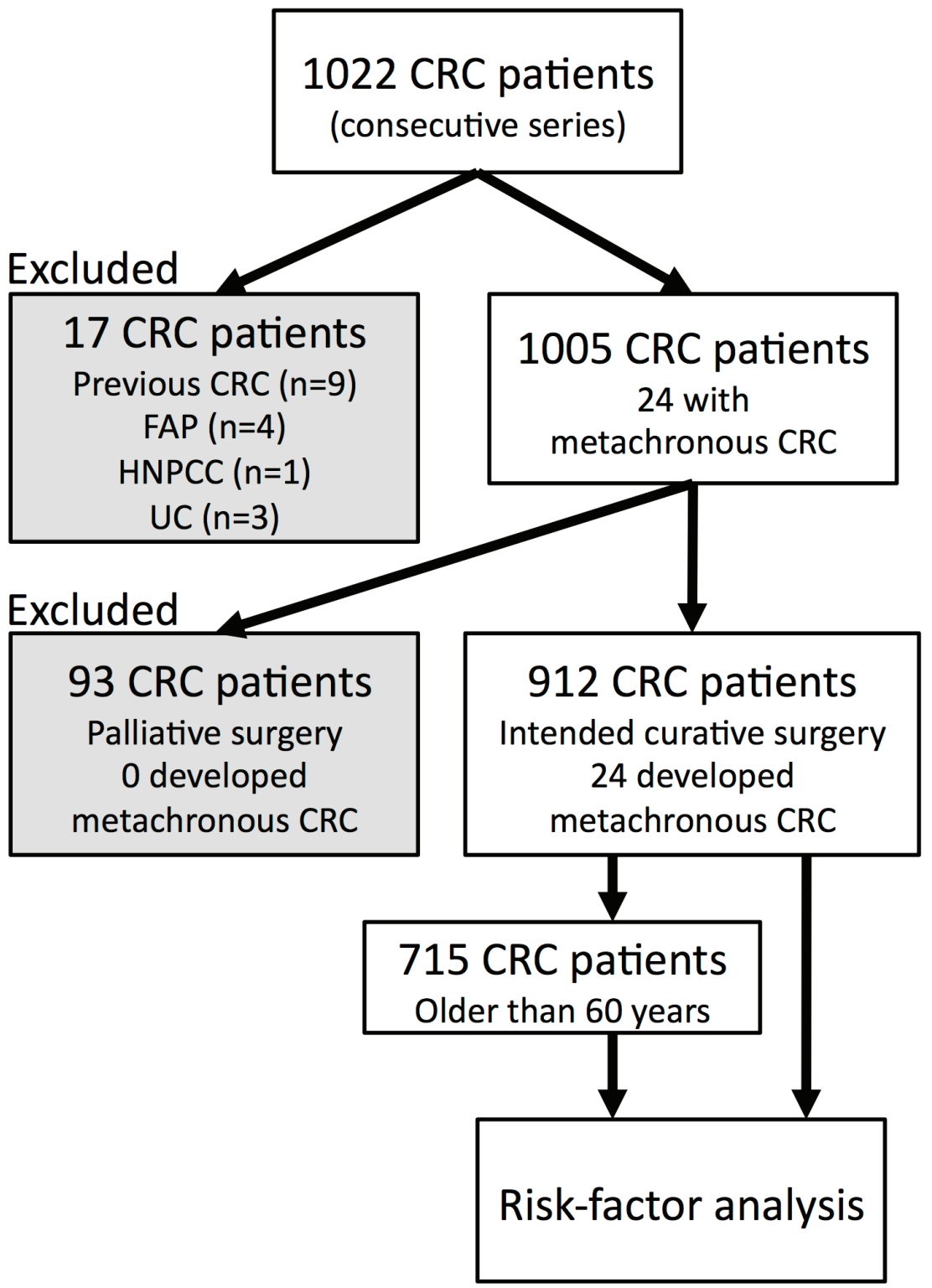

Figure 1: Scheme of the study design. Patients excluded from the study are in the grey-shaded boxes. Risk factor analysis was performed on 912 sporadic CRC patients that underwent intended curative surgery, and also on 715 of these patients that were older than 60 years. 
their median lifespan (12 months) was significantly shorter than the median time to develop a metachronous lesion (21.5 months, Figure S1). The follow-up period for the remaining 912 patients was 3,537 person-years (mean follow-up of 47.1 \pm 17.6 months). Most metachronous CRC developed within $3(n=19,79.2 \%)$ years after surgery. In $13(54.2 \%)$ of these patients, metachronous lesions were found in the first colonoscopy examination after surgery. Twenty (74\%) metachronous CRC were found in an early stage (Dukes A), but 7 (26\%) were in more advanced stages (Dukes B or C, Table S2).

Univariate Cox's proportional hazard regression analyses (Table 1) revealed that presence of synchronous $\mathrm{CRC}$ (hazard ratio $(\mathrm{HR})=5.24 ; 95 \%$ confidence intervals $\left.(\mathrm{CI})=2.17-12.65 ; p=2.3 \times 10^{-4}\right)$, tumor size $(\mathrm{HR}=1.16$ per $\mathrm{cm} ; \mathrm{CI}=1.01-1.33 ; p=0.037)$ and male gender (HR $=3.08 ; \mathrm{CI}=1.05-9.02 ; p=0.04)$ associated with higher risk for with metachronous CRC. Stenosis exhibited a borderline positive association with metachronous CRC risk $(\mathrm{HR}=2.3 ; \mathrm{CI}=0.98-5.37 ; p=0.055)$ and age also showed a positive association, but did not reach statistical significance $(\mathrm{HR}=1.03$ per year; $\mathrm{CI}=0.99-1.07 ; p=$ $0.14)$.

Multivariate Cox's proportional hazard regression considering the presence of synchronous tumors, gender, stenosis, tumor size and patient age (these last two parameters as dichotomous variables using the highest precision cutoff for classification, Figure S2), revealed that presence of synchronous tumors $(\mathrm{HR}=6.13 ; \mathrm{CI}=$ $\left.2.43-15.49 ; p=1.3 \times 10^{-4}\right)$ and tumor size $(\mathrm{HR}=4.34$; CI $\left.=1.80-10.42 ; p=1 \times 10^{-3}\right)$ were the only independent risk factors (Figure 2A).

When classifying patients according to the presence of synchronous tumors or to tumor size, patients with synchronous or solitary large $(\geq 6.5 \mathrm{~cm})$ had a much higher risk of developing metachronous lesions (Figure $2 \mathrm{~B}$ and $2 \mathrm{C}$ ). Grouping patients into high-risk (presence of synchronous tumors or solitary large tumors) and lowrisk (solitary small tumors) showed a very significant difference $\left(\mathrm{HR}=7.3 ; \mathrm{CI}=3.13-17.1 ; p=4.3 \times 10^{-6}\right.$, Figure 2D).

For all intended curative surgery patients, the standardized incidence ratio (SIR) was significantly higher for patients in the high-risk group compared with the general population in Japan. In contrast, patients in the low-risk group (with solitary small tumors) did not exhibit higher risk (Figure 2E).

We further refined the analysis by excluding 197 patients younger than 60 years old based on the rationale that some of them could be familiar CRC cases, undiagnosed due to incomplete family information in our retrospective database. After excluding these patients the observations remained essentially invariable with tumor size becoming stronger predictor (HR $=5.67$; CI: 2.29-14; $\left.p=1.7 \times 10^{-4}\right)$ than the presence of synchronous CRC (HR $\left.=5.34 ; \mathrm{CI}=1.97-14.4 ; p=9.7 \times 10^{-4}\right)($ Figure 3$)$.

\section{DISCUSSION}

We retrospectively studied the incidence of metachronous CRC in a consecutive series of 1,022 Japanese CRC patients. The incidence, time interval between the primary and the second cancer, and the stage of the metachronous tumors are in line with previous reports $[10,11]$. Our results indicate that the presence of synchronous CRC and the primary tumor size $\geq 6.5 \mathrm{~cm}$ are strong and independent risk factors for metachronous CRC. Gender and age at time of diagnosis only showed a borderline association with metachronous CRC risk. To the best of our knowledge our study is the first showing that tumor size is a strong and independent risk factor for metachronous CRC.

Presence of synchronous CRC, age, gender, tumor location, differentiation, and the existence of previous or concomitant extracolonic malignancies (ECM), have been proposed as risk factors for metachronous CRC [10-14]. Family history of malignancies has been also reported to increase the risk of metachronous CRC $[15,16]$. Due to the retrospective study design, the information regarding family history was not complete. The incidence of Hereditary Non-Polyposis Colorectal Cancer (HNPCC) in our series was low $(0.1 \%$, Figure 1$)$ even for the Japanese population [17], and it is possible that some participants were undiagnosed HNPCC. Nevertheless, HNPCC usually develops at a younger age [18], and only 2 of the $24 \mathrm{CRC}$ patients that developed metachronous CRC were diagnosed before 60 years. Moreover, all the observations remained essentially invariable after excluding patients younger than 60 years (Figure 3). Therefore, as patients with known hereditary cancer syndromes (as well as with inflammatory bowel disease) were excluded from the study, the etiology of the 27 metachronous CRCs that developed in our series cannot be explained by any known cancer predisposition condition.

Stenosis caused by large tumors may obstruct the advance of the colonoscope during preoperative surveillance, possibly hampering the detection of proximal synchronous CRCs. However, when stenosis was included as an explanatory factor in the multivariate analyses, it never reached statistical significance, while size remained a statistically significant independent risk factor (Figure 2A). Thus, the association between tumor size and metachronous CRC risk cannot be explained by the presence of undetected synchronous lesions hidden by stenosis.

Colon tumors with microsatellite instability (MSI) are usually larger than those without. The MSI status of the CRCs in our series is not known. Hence, it remains to be determined whether the large solitary tumors with higher risk for metachronous CRCs correspond to nonhereditary MSI cancers (as HNPCC were excluded), or whether MSI information could improve the proposed classification predictive power. Nevertheless, size-based 
Table 1: Association of clinical characteristics with development of metachronous CRC among 912 patients who underwent intended curative surgery

\begin{tabular}{|c|c|c|c|c|}
\hline & $\begin{array}{l}\text { Without mCRC } \\
(n=888 ; 97.4 \%)\end{array}$ & $\begin{array}{l}\text { With mCRC } \\
(n=24 ; 2.6 \%)\end{array}$ & $\begin{array}{l}\text { Hazard ratio and } 95 \% \\
\text { confidence interval }\end{array}$ & $p$-value \\
\hline Gender (male/female) No. & $554 / 334$ & $20 / 4$ & $3.08(1.05-9.02)$ & 0.04 \\
\hline Mean Age, years \pm SD & $67.5 \pm 11.3$ & $70.5 \pm 7.5$ & $1.03(.99-1.07)$ per yr & 0.14 \\
\hline Follow-up months \pm SD & $47.1 \pm 17.6$ & $49.8 \pm 17.3$ & $0.98(0.95-1.01)$ & 0.25 \\
\hline Location (first lesion) & & & $1.55(0.62-3.91)$ & 0.35 \\
\hline Right-side & $302(34.0 \%)$ & $7(29.2 \%)$ & & \\
\hline Left-side & $279(31.4 \%)$ & $11(45.8 \%)$ & & \\
\hline Rectum & $307(34.6 \%)$ & $6(25 \%)$ & & \\
\hline Average size; $\mathrm{mm} \pm \mathrm{SD}$ & $42.2 \pm 22.6$ & $51.8 \pm 21.0$ & $1.16(1.01-1.33)$ per $\mathrm{cm}$ & 0.037 \\
\hline $\mathrm{T}$ factor & & & $1.39(0.55-3.51)$ & 0.48 \\
\hline Tis & $32(3.6 \%)$ & $0(0)$ & & \\
\hline $\mathrm{T} 1$ & $99(11.1 \%)$ & $2(8.3 \%)$ & & \\
\hline $\mathrm{T} 2$ & $142(16 \%)$ & $4(16.7 \%)$ & & \\
\hline $\mathrm{T} 3$ & $445(50.1 \%)$ & $11(45.8 \%)$ & & \\
\hline $\mathrm{T} 4$ & $167(18.8 \%)$ & $7(29.2 \%)$ & & \\
\hline No residual & $3(0.3 \%)$ & $0(0)$ & & \\
\hline Differentiation & & & $1.45(0.18-10.7)$ & 0.72 \\
\hline pap + well + mod & $862(97.1 \%)$ & $23(95.8 \%)$ & & \\
\hline poor + muc + sig & $26(2.9 \%)$ & $1(4.2 \%)$ & & \\
\hline Lymph node metastasis & & & $1.48(0.66-3.33)$ & 0.35 \\
\hline N0 & $585(65.9 \%)$ & $14(58.3 \%)$ & & \\
\hline $\mathrm{N} 1 / 2 / 3 / 4$ & $303(34.1 \%)$ & $10(41.7 \%)$ & & \\
\hline Dukes, No. & & & $1.37(0.61-3.08)$ & 0.45 \\
\hline A & $227(25.6 \%)$ & $4(16.7 \%)$ & & \\
\hline $\mathrm{B}$ & $341(38.4 \%)$ & $10(41.7 \%)$ & & \\
\hline $\mathrm{C}$ & $285(32.1 \%)$ & $9(37.5 \%)$ & & \\
\hline $\mathrm{D}$ & $35(3.9 \%)$ & $1(4.2 \%)$ & & \\
\hline Survival & & & & 0.37 \\
\hline 3 years & $89.0 \%$ & $91.2 \%$ & & \\
\hline 5 years & $82.0 \%$ & $72.9 \%$ & & \\
\hline Solitary/Synchronous & & & $5.24(2.17-12.65)$ & $<0.001$ \\
\hline Solitary CRC & $822(92.6 \%)$ & $17(70.8 \%)$ & & \\
\hline Synchronous CRC & $66(7.4 \%)$ & $7(29.2 \%)$ & & \\
\hline Extracolonic Malignancy Malignancies & & & $1.89(0.65-5.55)$ & 0.24 \\
\hline No ECM & $795(89.5 \%)$ & $20(83.3 \%)$ & & \\
\hline ECM & $93(10.5 \%)$ & $4(16.7 \%)$ & & \\
\hline Stenosis & & & $2.30(0.98-5.37)$ & 0.055 \\
\hline No & $719(81.0 \%)$ & $16(66.7 \%)$ & & \\
\hline Yes & $169(19.0 \%)$ & $8(33.3 \%)$ & & \\
\hline
\end{tabular}

$P$-values calculated by Cox's proportional hazard regression, except for survival, where logrank test was employed.

Significant values $(<0.05)$ in bold. For location, right side vs. left side + rectum tumors. For T factor, Tis, T1 and T2 vs.

T3 and T4. For stage, Dukes' A and B vs. C and D. mCRC: metachronous CRC; pap: papillary; mod: moderate; muc:

mucinous; sig: signet ring. 


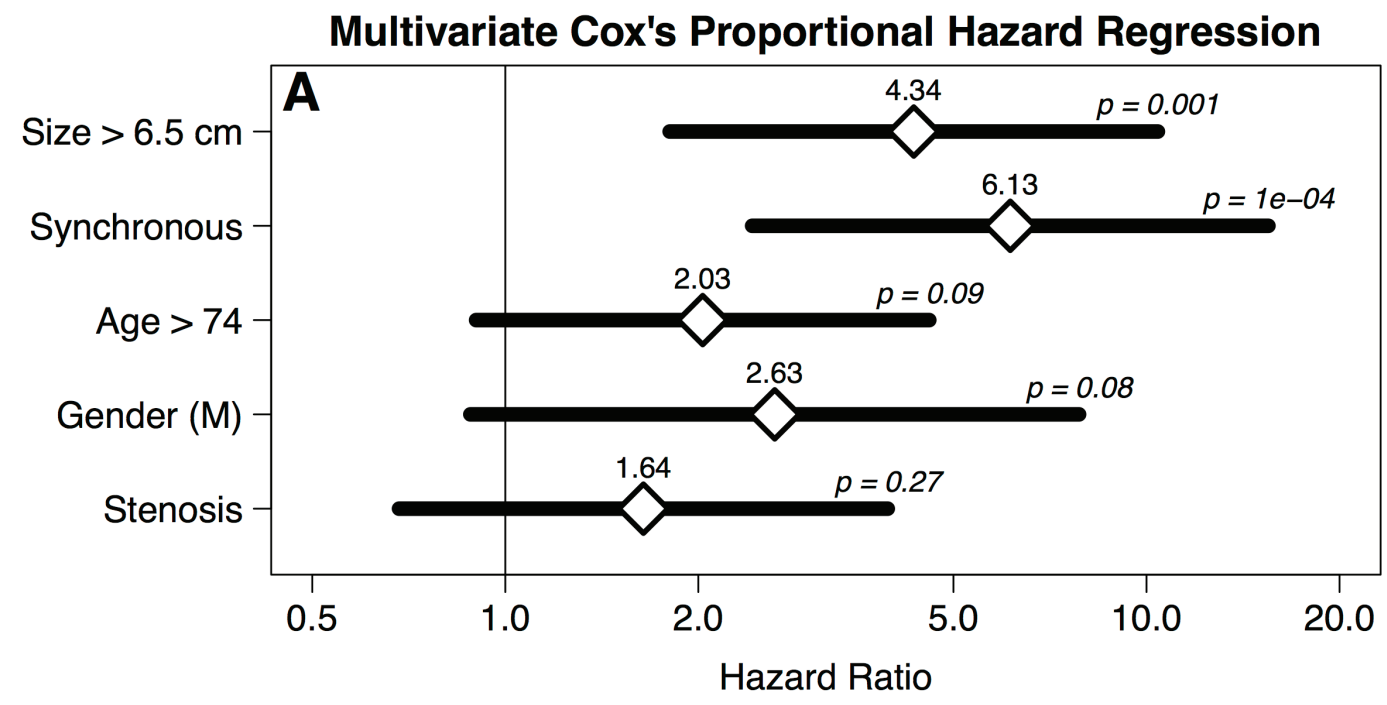

Metachronous CRC Incidence
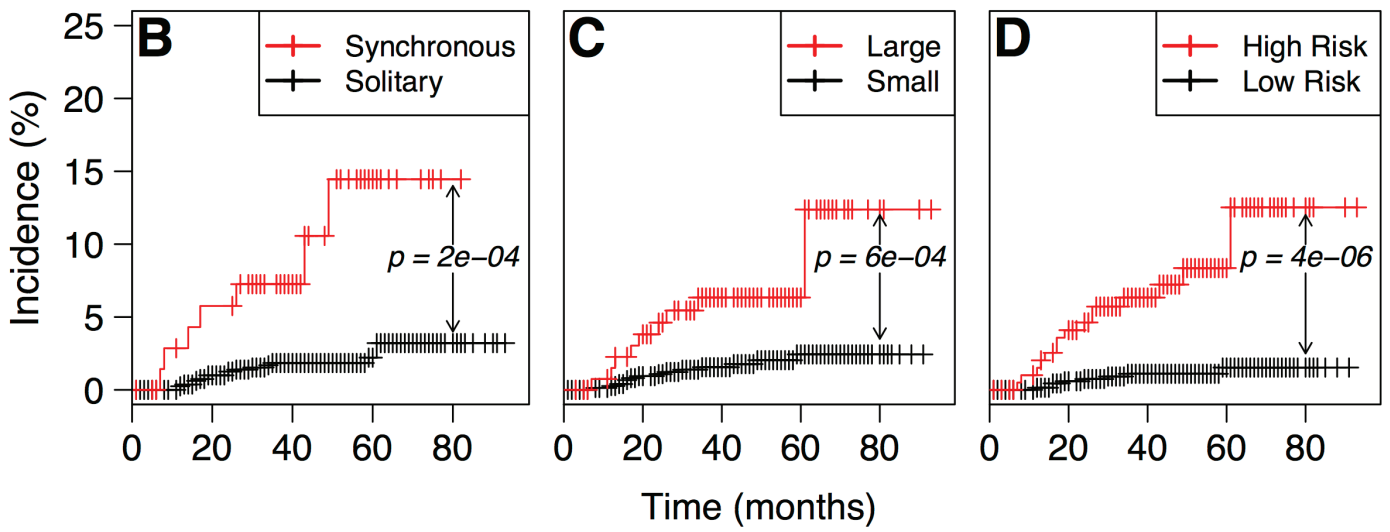

\section{Standarized Incidence Ratio}

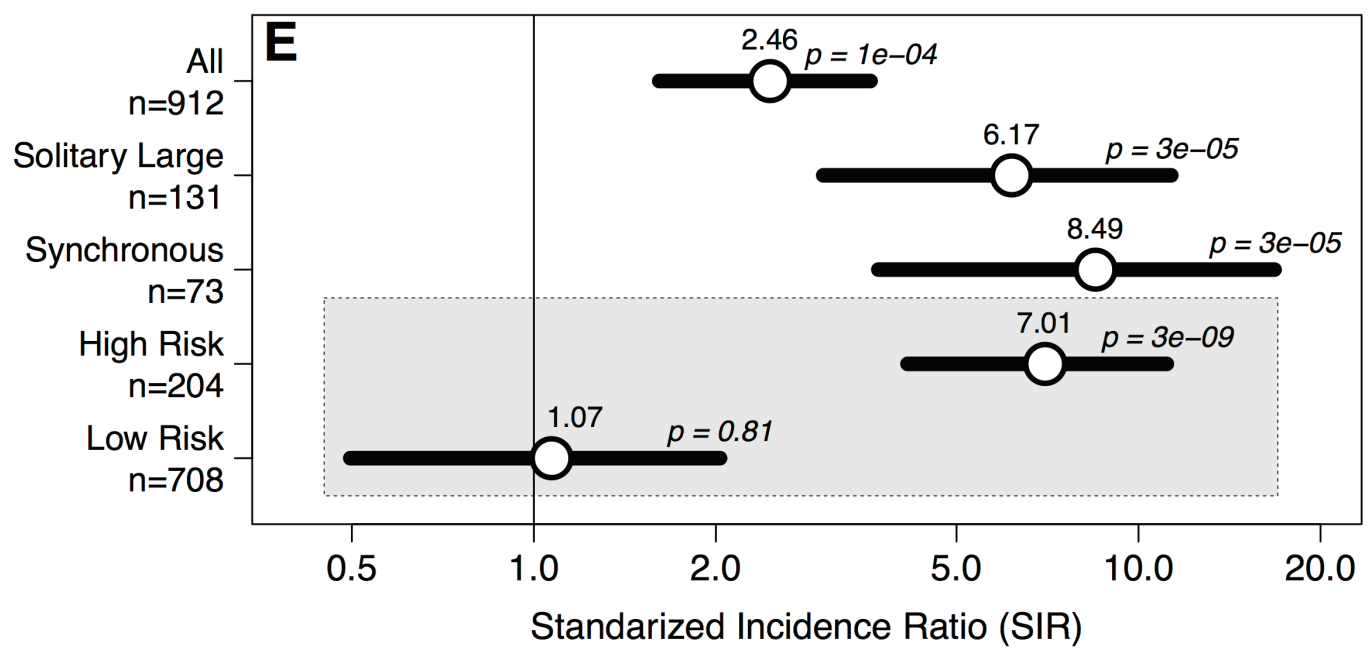

Figure 2: A. Multivariate Cox's proportional hazard regression of metachronous CRC incidence in patients with intended curative surgery. Diamonds indicate hazard ratios, horizontal bars indicate confidence intervals. B.-D. Metachronous CRC incidence in patients stratified according to B. synchronous $v s$ solitary tumors, C. size of the tumor and D. high-risk (synchronous or solitary large, red) $v s$. low risk (solitary small, black). $P$-values calculated by Cox's proportional hazards method. E. Standardized incidence ratio of metachronous CRC development in all patients, patients with solitary large tumors, patients with synchronous tumors, patients with any of these two features (high-risk) and patients with solitary small tumors (low-risk). $P$-values calculated by mid-P method. 


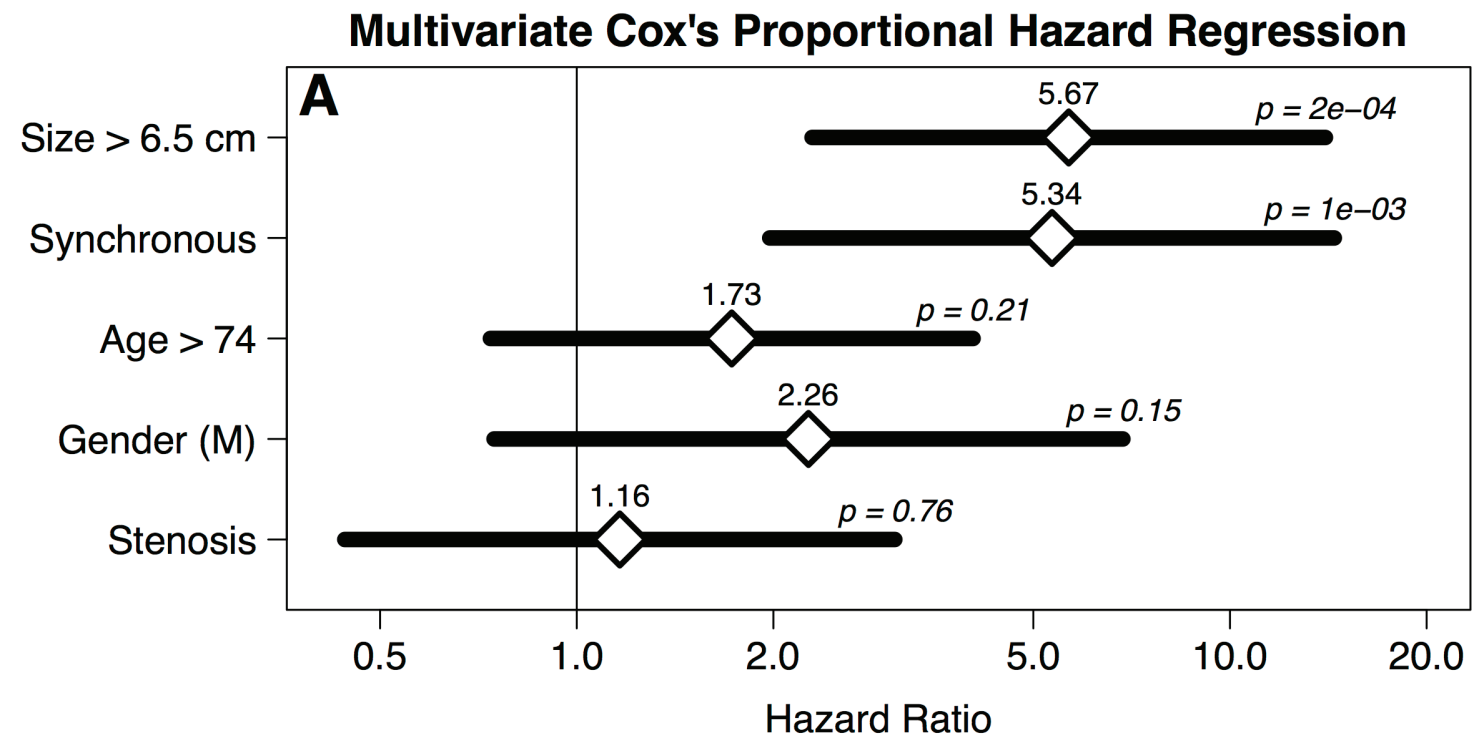

Metachronous CRC Incidence
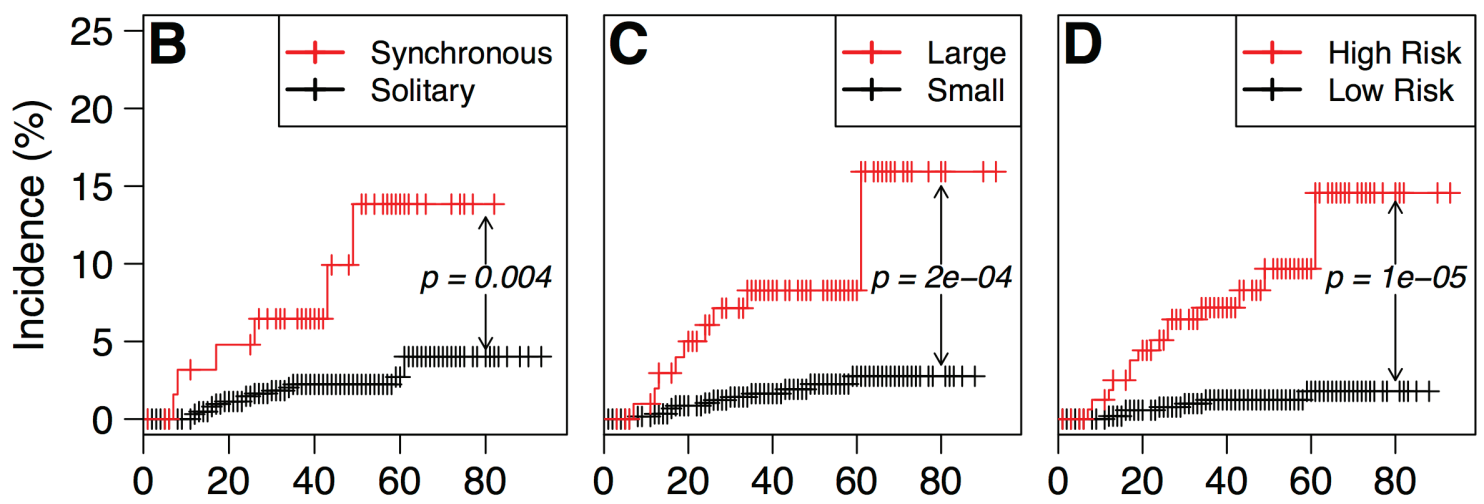

Time (months)

Standarized Incidence Ratio

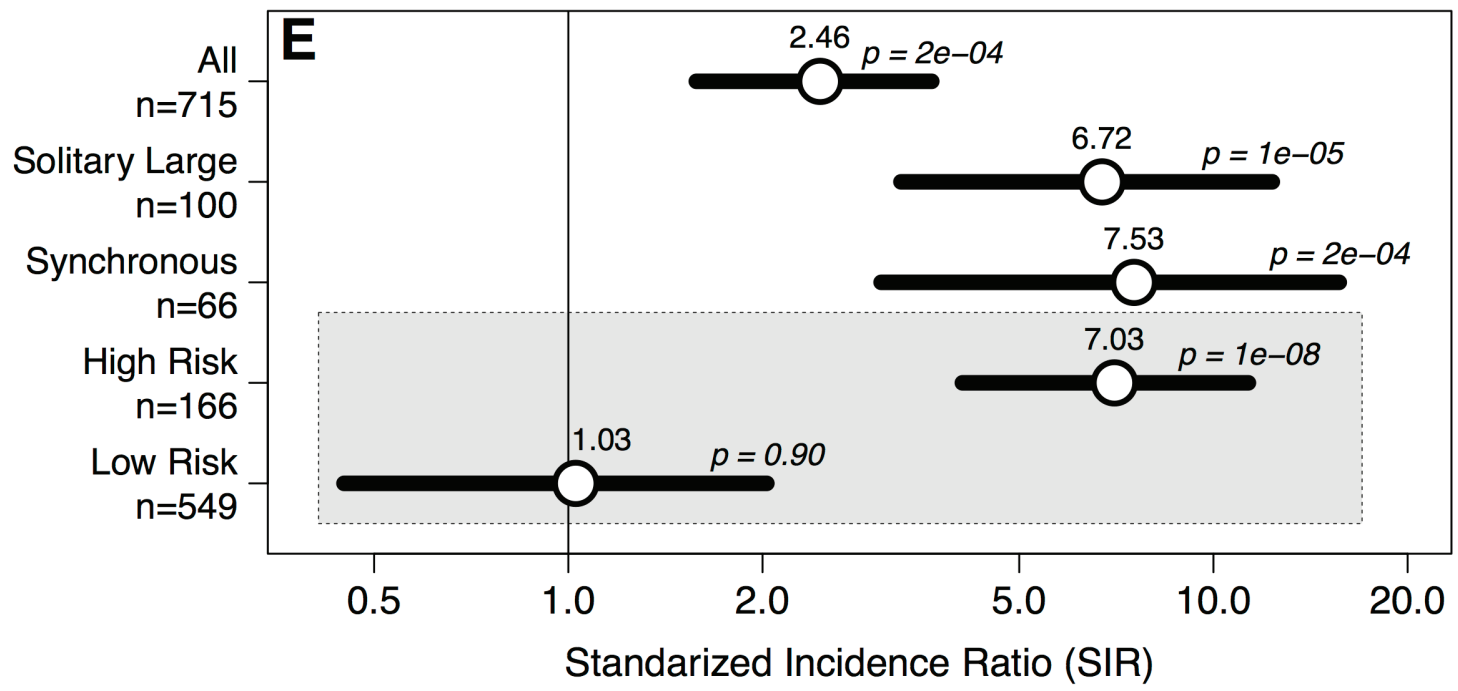

Figure 3: A. Multivariate Cox's proportional hazard regression of metachronous CRC incidence in patients with intended curative surgery older than 60 years. Symbols and methods are as in Figure 2. 
classification has a practical advantage, especially in areas or countries with limited resources for more sophisticated pathological or molecular analyses.

In Japan there are no consensus guidelines for surveillance colonoscopy after surgery. Nevertheless, in our department we recommend the patients to undergo colonoscopy 1 year after surgery. Regrettably, compliance with this recommendation is not $100 \%$, which is a common situation also reported in other studies where the adherence to the colonoscopy ranged between 18-61\% [9]. This is an important issue that needs to be overcome and our study should help by clearly defining a simple criterion for selecting high-risk patients.

The molecular basis for the higher metachronous $\mathrm{CRC}$ risk in patients with synchronous or solitary large colonic tumors remains to be elucidated. We previously reported that genome-wide demethylation of the mucosa adjacent to the primary CRC associates with higher incidence of synchronous and metachronous colon tumors [19]. The concept of an epigenetic field for cancerization in $\mathrm{CRC}$, i.e. epigenetic disregulation affecting the colonic tissue and predisposing to its malignant transformation, has been explored by us and other authors [19-27]. However, it is still unknown whether this phenomenon is circumscribed to a small region of the colon, affects the whole organ, or is systemic, reflecting a still uncharacterized predisposition to accelerated DNA demethylation $[19,28]$.

In conclusion, based on our results we propose that post-operative surveillance programs for patients who undergo curative $\mathrm{CRC}$ resection can be improved by stratifying patients into high vs. low risk groups, according to tumor size and presence of synchronous tumors.

\section{MATERIALS AND METHODS}

\section{Patients}

A total of 1022 consecutive patients underwent surgery for primary CRC in Saitama Medical Center, Jichi Medical University between January 2007 and December 2011. Altogether 17 cases of hereditary cancer syndromes or inflammatory bowel disease were excluded (Figure 1). Mean follow-up was $44.3 \pm 19.5$ months and mean patient age was $67.4 \pm 11.2$ years. Metachronous CRC (metachronous CRC) was defined according to the criteria of Moertel et al. [29] as follows: a pathologically proven adenocarcinoma, distinctly separated from the previous line of anastomosis, and diagnosed at a minimal interval of 6 months after the initial carcinoma. Tumors diagnosed within 6 months after the initial diagnosis were considered as synchronous CRC. In synchronous CRCs identified at the time of operation, the index lesion was considered to be the most pathologically advanced tumor. When two or more lesions were at an identical pathological stage, the largest tumor was considered the index lesion and the other lesions were designated as the concurrent lesions. In metachronous CRCs, the carcinoma diagnosed at the prior operation was considered the primary lesion. All synchronous and metachronous tumors were carcinomas.

Tumor location was classified into right colon (appendix, cecum, ascending, hepatic flexure and transverse), left colon (splenic flexure, descending, sigmoid, and rectosigmoid junction) and rectum [30]. Tumor size was defined as the length of its major axis, measured after surgery by using a millimeter ruler. Patients harboring locally advanced tumors that prevented colonoscopic examination of the proximal colon were defined as "stenosis" cases. These patients received an alternative surveillance modality, e.g. 3D-Computed tomography, barium enema study, colonoscopy after selfextended metallic stem placement across the obstructing lesion or intra-operative colonoscopy.

\section{Calculation of standardized incidence ratio}

The standardized incidence ratio (SIR) was calculated as the ratio of the observed to the expected number of patients developing CRCs [31]. The expected number was determined using age-stratified and sexspecific data on the incidence of cancer in Japan, provided by the Center for Cancer Control and Information Services, National Cancer Center Japan [32]. Age between surgery for primary CRC and the end of the follow-up period, or age between primary surgery and the time of diagnosis of metachronous CRC, was employed to individually determine the expected incidence for every patient.

\section{Statistical analysis}

Differences in survival and metachronous CRC incidence were studied using Cox's proportional hazards regression. Differences were considered statistically significant at $p<0.05$. Statistical analyses were performed using the $\mathrm{R}$ environment for statistical computing and the OpenEpi statistical calculator [33, 34].

\section{Ethics statement}

In this retrospective study, we analyzed anonymized clinical information from patients from the Saitama Medical Center, Jichi Medical University. The study was approved by the Research Ethics Committee at Saitama Medical Center, Jichi Medical University, complying with the ethical guidelines of the Declaration of Helsinki [35]. 


\section{CONFLICTS OF INTEREST}

The authors declare that they have no conflict of interest.

\section{GRANT SUPPORT}

No specific funding was granted to support this study.

\section{Editorial note}

This paper has been accepted based in part on peerreview conducted by another journal and the authors' response and revisions as well as expedited peer-review in Oncotarget.

\section{REFERENCES}

1. Jemal A, Bray F, Center MM, Ferlay J, Ward E, Forman D. Global cancer statistics. CA Cancer J Clin. 2011; 61:69-90.

2. Sung JJ, Lau JY, Goh KL, Leung WK, Asia Pacific Working Group on Colorectal C. Increasing incidence of colorectal cancer in Asia: implications for screening. Lancet Oncol. 2005; 6:871-876.

3. Yiu HY, Whittemore AS, Shibata A. Increasing colorectal cancer incidence rates in Japan. Int J Cancer. 2004; 109:777-781.

4. Yee YK, Tan VP, Chan P, Hung IF, Pang R, Wong BC. Epidemiology of colorectal cancer in Asia. J Gastroenterol Hepatol. 2009; :1810-1816.

5. Lu JB, Sun XB, Dai DX, Zhu SK, Chang QL, Liu SZ, Duan WJ. Epidemiology of gastroenterologic cancer in Henan Province, China. World J Gastroenterol. 2003; 9:24002403.

6. Yang L, Parkin DM, Li LD, Chen YD, Bray F. Estimation and projection of the national profile of cancer mortality in China: 1991-2005. Br J Cancer. 2004; 90:2157-2166.

7. Shureiqi I, Cooksley CD, Morris J, Soliman AS, Levin B, Lippman SM. Effect of age on risk of second primary colorectal cancer. J Natl Cancer Inst. 2001; 93:1264-1266.

8. Gilberson R. Asking and Answering Provocative Questions. Cancer Discovery. 2011; 1:1.

9. Carpentier MY, Vernon SW, Bartholomew LK, Murphy $\mathrm{CC}$, Bluethmann SM. Receipt of recommended surveillance among colorectal cancer survivors: a systematic review. J Cancer Surviv. 2013; 7:464-483.

10. Togashi K, Konishi F, Ozawa A, Sato T, Shito K, Kashiwagi H, Okada M, Nagai H. Predictive factors for detecting colorectal carcinomas in surveillance colonoscopy after colorectal cancer surgery. Dis Colon Rectum. 2000; 43:S47-53.

11. Park IJ, Yu CS, Kim HC, Jung YH, Han KR, Kim JC.
Metachronous colorectal cancer. Colorectal Dis. 2006; 8:323-327.

12. Leggett BA, Cornwell M, Thomas LR, Buttenshaw RL, Searle J, Young J, Ward M. Characteristics of metachronous colorectal carcinoma occurring despite colonoscopic surveillance. Dis Colon Rectum. 1997; 40:603-608.

13. Latournerie M, Jooste V, Cottet V, Lepage C, Faivre J, Bouvier AM. Epidemiology and prognosis of synchronous colorectal cancers. Br J Surg. 2008; 95:1528-1533.

14. Soreide K, Gudlaugsson E, Skaland I, Janssen EA, Van Diermen B, Korner H, Baak JP. Metachronous cancer development in patients with sporadic colorectal adenomasmultivariate risk model with independent and combined value of hTERT and survivin. Int J Colorectal Dis. 2008; 23:389-400.

15. Lynch HT, Lanspa SJ, Boman BM, Smyrk T, Watson P, Lynch JF, Lynch PM, Cristofaro G, Bufo P, Tauro AV, et al. Hereditary nonpolyposis colorectal cancer-Lynch syndromes I and II. Gastroenterol Clin North Am. 1988; 17:679-712.

16. Samadder NJ, Curtin K, Wong J, Tuohy TM, Mineau GP, Smith KR, Pimentel R, Pappas L, Boucher K, GarridoLaguna I, Provenzale D, Burt RW. Epidemiology and familial risk of synchronous and metachronous colorectal cancer: a population-based study in Utah. Clin Gastroenterol Hepatol. 2014; 12:2078-2084 e2071-2072.

17. Fujita S, Moriya Y, Sugihara K, Akasu T, Ushio K. Prognosis of hereditary nonpolyposis colorectal cancer (HNPCC) and the role of Japanese criteria for HNPCC. Jpn J Clin Oncol. 1996; 26:351-355.

18. Hampel H, Frankel WL, Martin E, Arnold M, Khanduja K, Kuebler P, Nakagawa H, Sotamaa K, Prior TW, Westman J, Panescu J, Fix D, et al. Screening for the Lynch syndrome (hereditary nonpolyposis colorectal cancer). N Engl J Med. 2005; 352:1851-1860.

19. Kamiyama H, Suzuki K, Maeda T, Koizumi K, Miyaki Y, Okada S, Kawamura YJ, Samuelsson JK, Alonso S, Konishi F, Perucho M. DNA demethylation in normal colon tissue predicts predisposition to multiple cancers. Oncogene. 2012; 31:5029-5037.

20. Alonso S, Dai Y, Yamashita K, Horiuchi S, Dai T, Matsunaga A, Sanchez-Munoz R, Bilbao-Sieyro C, Diaz-Chico JC, Chernov AV, Strongin AY, Perucho M. Methylation of MGMT and ADAMTS14 in normal colon mucosa: biomarkers of a field defect for cancerization preferentially targeting elder AfricanAmericans. Oncotarget. 2015; 6:3420-3431. doi: 10.18632/ oncotarget.2852.

21. Koizumi K, Alonso S, Miyaki Y, Okada S, Ogura H, Shiiya N, Konishi F, Taya T, Perucho M, Suzuki K. Array-based identification of common DNA methylation alterations in ulcerative colitis. Int J Oncol. 2012; 40:983-994.

22. Luo Y, Yu M, Grady WM. Field cancerization in the colon: a role for aberrant DNA methylation? Gastroenterol Rep 
(Oxf). 2014; 2:16-20.

23. Shen L, Kondo Y, Rosner GL, Xiao L, Hernandez NS, Vilaythong J, Houlihan PS, Krouse RS, Prasad AR, Einspahr JG, Buckmeier J, Alberts DS, et al. MGMT promoter methylation and field defect in sporadic colorectal cancer. J Natl Cancer Inst. 2005; 97:1330-1338.

24. Ushijima T. Epigenetic field for cancerization: its cause and clinical implications. BMC Proc. 2013; 7 Suppl 2:K22.

25. Nakajima T, Enomoto S, Ushijima T. DNA methylation: a marker for carcinogen exposure and cancer risk. Environ Health Prev Med. 2008; 13:8-15.

26. Ushijima T. Epigenetic field for cancerization. J Biochem Mol Biol. 2007; 40:142-150.

27. Zhuo C, Li Q, Wu Y, Li Y, Nie J, Li D, Peng J, Lian P, Li B, Cai G, Li X, Cai S. LINE-1 hypomethylation in normal colon mucosa is associated with poor survival in Chinese patients with sporadic colon cancer. Oncotarget. 2015; 6:23820-23836. doi: 10.18632/oncotarget.4450.

28. Brennan K, Flanagan JM. Is there a link between genomewide hypomethylation in blood and cancer risk? Cancer Prev Res (Phila). 2012; 5:1345-1357.

29. Moertel CG, Bargen JA, Dockerty MB. Multiple carcinomas of the large intestine: a review of the literature and a study of 261 cases. Gastroenterology. 1958; 34:85-98.
30. Oya M, Takahashi S, Okuyama T, Yamaguchi M, Ueda Y. Synchronous colorectal carcinoma: clinico-pathological features and prognosis. Jpn J Clin Oncol. 2003; 33:38-43.

31. Kawakubo K, Tada M, Isayama H, Sasahira N, Nakai Y, Yamamoto K, Kogure H, Sasaki T, Hirano K, Ijichi H, Tateishi K, Yoshida H, et al. Incidence of extrapancreatic malignancies in patients with intraductal papillary mucinous neoplasms of the pancreas. Gut. 2011; 60:1249-1253.

32. Matsuda T, Marugame T, Kamo K, Katanoda K, Ajiki W, Sobue T, Japan Cancer Surveillance Research G. Cancer incidence and incidence rates in Japan in 2006: based on data from 15 population-based cancer registries in the monitoring of cancer incidence in Japan (MCIJ) project. Jpn J Clin Oncol. 2012; 42:139-147.

33. Sullivan KM, Dean A, Soe MM. OpenEpi: a web-based epidemiologic and statistical calculator for public health. Public Health Rep. 2009; 124:471-474.

34. R Core Team. R: A language and environment for statistical computing. R Foundation for Statistical Computing, Vienna, Austria. 2015. URL https://www.R-project.org/.

35. World Medical A. World Medical Association Declaration of Helsinki: ethical principles for medical research involving human subjects. JAMA. 2013; 310:2191-2194. 